\title{
LIMITES À RESPONSABILIDADE SOLIDÁRIA AMBIENTAL E À CARACTERIZAÇÃO DO POLUIDOR INDIRETO ${ }^{1}$
}

\author{
Délton Winter de Carvalho ${ }^{2}$ \\ Universidade do Vale do Rio dos Sinos (UNISINOS)
}

\begin{abstract}
RESUMO
No Brasil há uma visível carência na atualização da reflexão jurídica dos critérios justificadores da incidência do instituto da solidariedade nos casos de responsabilidade civil ambiental, sobretudo quanto a seus limites. A ampliação irrestrita e alheia às complexidades técnicas e fáticas de determinado dano ambiental, pode redundar em assimetrias, desequilíbrios e perda do caráter dissuasório (por excesso). Ao revés, a aplicação consolidada e definida dos casos sujeitos e os limites do instituto tendem a fortalecer a proteção ambiental, tal como, a desejável estabilidade das relações socioeconômicas. Nesse sentido, o artigo visa lançar luzes ao tema ainda tormentoso no Direito Ambiental, quanto aos critérios definidores dos limites da incidência do instituto da solidariedade e a definição de poluidor indireto. Para tanto, se utiliza de reflexões sistêmicas, com enfoque nos sistemas jurídico e econômico, e de pesquisa documental, com grande ênfase no direito comparado, a partir das experiências de países industrializados que enfrentaram problemas de contaminação ambiental-industrial e que têm compatibilidade com o sistema e tradição jurídica brasileira. Os critérios de definição e aplicação desses institutos passam a ser de fundamental importância para a obtenção de uma proteção ambiental eficiente e exercida em equilíbrio com as dimensões da sustentabilidade.
\end{abstract}

Palavras-chave: deveres de segurança ambiental; poluidor indireto; responsabilidade civil ambiental; solidariedade.

\footnotetext{
$1 \mathrm{O}$ presente trabalho foi realizado com apoio do Conselho Nacional de Desenvolvimento Científico e Tecnológico (CNPq), por meio da Chamada MCTIC/CNPq n. 28/2018 - Universal/Faixa B.

2 Pós-doutor pela University of California, Berkeley. Doutor em Direito pela UNISINOS. Professor da Universidade do Vale do Rio dos Sinos. Graduado em Direito pela UNISINOS. Professor do Programa de Pós-Graduação Stricto Sensu da UNISINOS. ORCID: https://orcid.org/0000-0001-9469-5779 / e-mail: delton@deltoncarvalho.com.br
} 


\section{LIMITS TO ENVIRONMENTAL SOLIDARITY RESPONSIBILITY AND}

INDIRECT POLLUTER CHARACTERIZATION

\section{ABSTRACT}

In Brazil, there is a visible lack of updating the legal reflection of the criteria that justify the incidence of the solidarity institute in cases of environmental civil liability, especially regarding its limits. The unrestricted expansion and oblivious to the technical and factual complexities of a given environmental damage, can result in asymmetries, imbalances and loss of deterrent character (by excess). On the contrary, the consolidated and defined application of the subject cases and the limits of the institute tend to strengthen environmental protection, as well as the desirable stability of socioeconomic relations. In this sense, the article aims to shed light on the still stormy theme in Environmental Law, regarding the criteria that define the limits of the incidence of the solidarity institute and the definition of indirect polluter. For that, it uses systemic reflections, focusing on the legal and economic systems, and documentary research, with a great emphasis on comparative law, based on the experiences of industrialized countries that faced problems of environmental-industrial contamination and that are compatible with the environment. Brazilian legal system and tradition. The criteria for the definition and application of these institutes are of fundamental importance for obtaining efficient environmental protection and exercised in balance with the dimensions of sustainability.

Keywords: environmental liability; environmental safety duties; indirect polluter; joint and several liability. 


\section{INTRODUÇÃO}

Apesar de uma consolidação significativa e consensual acerca do princípio da solidariedade em matéria ambiental, a análise mais detalhada ainda é pertinente para desvelar os critérios que justificam e, consequentemente, limitam sua aplicação. Se da solidariedade há algum consenso, a matéria pertinente ao poluidor indireto e aos critérios jurídicos interpretativos para sua incidência mostram-se tormentosos para a doutrina e jurisprudência.

É nesse objeto que o presente artigo lança sua pretensão de refletir profundamente acerca dos critérios para incidência da solidariedade para todos que contribuem para um dano ambiental e, em face desses critérios, a delimitação dos limites do instituto. Também se enfrenta o problema da formação e definição dos critérios jurídicos para a delimitação interpretativa da responsabilidade solidária e do poluidor indireto. Por fim, se analisa, conceitualmente, a noção da figura do indireto, como agente que, apesar de não estar diretamente vinculado à atividade causadora do dano, teria o dever de intervir e fiscalizar a atividade para evitar a concretização da lesão ambiental, pois, quando não o faz, torna-se corresponsável pelos danos.

A pesquisa está metodologicamente assentada na análise das estruturas do Direito pátrio, assim como nas experiências havidas no Direito comparado, quando compatíveis com o nosso sistema jurídico. A justificativa para a análise do Direito comparado se dá pelo fato de países industrializados já terem sido expostos e enfrentaram em seus tribunais e doutrina diversos dos problemas aqui ora debatidos, ainda efervescentes no cenário jurídico nacional.

$\mathrm{Na}$ busca de se revelar quais os critérios delimitadores dos conceitos aqui enfrentados, almeja-se fornecer relações jurídicas estáveis e seguras que, ao mesmo tempo, refletirão no alcance de uma ambiciosa e eficiente proteção ambiental no território brasileiro.

\section{A RESPONSABILIDADE SOLIDÁRIA EM MATÉRIA AMBIENTAL}

A solidariedade consiste em modalidade de obrigação prevista no direito civil pátrio, segundo a qual há a multiplicidade de sujeitos, seja pela concorrência de vários credores, cada um com o direito à integralidade da dívida (solidariedade ativa) ou, ainda, pela pluralidade de devedores, cada 
um obrigado por sua totalidade (solidariedade passiva). Assim, segundo o art. 264 do Código Civil, "há solidariedade, quando na mesma obrigação concorre mais de um credor, ou mais de um devedor, cada um com direito, ou obrigado, à dívida toda" (BRASIL, 2002).

No âmbito da reparação de danos, observa-se um "fenômeno de expansão da solidariedade passiva na reparação de danos injustos" (CAVALIERI FILHO, 2012, p. 64) para casos de "causalidade comum" (FARIAS; ROSENVALD, 2012, p. 321), em que duas ou mais pessoas concorrem efetivamente para a produção de um dano. O Código Civil previu que, em havendo mais de um causador do dano, todos são responsáveis pela reparação, conforme estabelece o art. 942 do Código Civil. Aliás, na solidariedade existe uma pluralidade subjetiva (de credores ou devedores) e uma unidade objetiva que prevê, nos termos do art. 264 do Código Civil, que "há a solidariedade, quando na mesma obrigação concorre mais de um credor, ou mais de um devedor, cada um com direito, ou obrigado, à dívida toda" (FARIAS; ROSENVALD, 2012, p. 297).

A solidariedade, inegavelmente, guarda relação com o estudo do nexo causal, sendo frequentemente descrita a partir da existência de danos decorrentes de uma causalidade comum, causalidade complexa ou mesmo uma dispersão causal (BENJAMIN, 1998; CAVALIERI FILHO, 2012; LEMOS, 2014). Em matéria de responsabilidade ambiental aplica-se o princípio da responsabilização dentro dos limites e previsões semânticas inseridos no art. 225, $\S 3^{\circ}$, da Constituição Federal. Nessa matéria, a responsabilidade civil aplica-se na modalidade objetiva, prevista no art. $14, \S 1^{\circ}$, da Lei n. 6.938/81. Note-se que tanto o texto constitucional (art. $225, \S 3^{\circ}$ ) quanto a legislação infraconstitucional (art. $14, \S 1^{\circ}$, da Lei n. 6.938/81) remetem à regra geral da imprescindibilidade de demonstração do nexo causal, a partir das expressões "condutas e atividades consideradas lesivas", no primeiro caso, e "afetados por sua atividade", no segundo. Por óbvio, sem tais demonstrações causais não há que se falar em responsabilidade civil ambiental, qualquer que seja a modalidade de teoria do risco adotada. Nesse sentido, enfatiza o entendimento de Silva (1994), ao prever a responsabilidade civil daqueles que contribuíram para determinado dano: "Aplicam-se as regras da solidariedade entre os responsáveis, podendo a reparação ser exigida de todos e de qualquer um dos responsáveis".

A incidência generalizada da solidariedade em matéria ambiental tem decorrido tanto da regra geral prevista no art. 942 do Código Civil, como em virtude de referência, em legislação específica ambiental, à figura do 
poluidor, em suas facetas do direto e do indireto. Esse é o caso do art. $3^{\circ}$, III e IV, da Lei n. 6.938/81. Existem, ainda, leis específicas que, diversamente da legislação ambiental geral, fazem referência expressa à responsabilidade solidária. Em matéria ambiental, a solidariedade é justificada para resolver casos em que múltiplos atores e atividades contribuem para a ocorrência de um dano ambiental, desonerando o autor da ação em ter que demonstrar a contribuição exata de cada um dos partícipes, podendo exigir a integralidade dos custos da reparação de qualquer um dos corresponsáveis.

Diante do texto literal apresentado no conceito de poluidor do art. $3^{\circ}$, IV, da Lei n. 6.938/81, não restam dúvidas de que respondem solidariamente todos aqueles que contribuam (ação ou omissão) direta ou indiretamente para a ocorrência de danos ambientais. A responsabilidade civil por danos ambientais faz-se extremamente ampla, podendo vir a ser responsabilizados pelos danos ambientais pessoas físicas, pessoas jurídicas de direito público ou privado e entes despersonalizados (BENJAMIN, 1998). Em outras palavras, todos aqueles que contribuam de alguma maneira para a ocorrência de um dano ambiental devem responder pela integralidade do dano, cabendo a repartição dos prejuízos internamente entre os causadores do dano, por meio do exercício do direito de regresso por aquele que indenizou ou reparou os danos em montante excedente a seu percentual de participação na lesão ambiental. Contudo, a regra geral consiste em que, não havendo demonstração de contribuição, inexiste responsabilidade civil em matéria ambiental.

Em adição, e ciente de que boa parte dos danos ambientais tem em sua fonte a pluralidade dos agentes e uma multiplicidade de fontes, a doutrina e a jurisprudência ${ }^{3}$, têm, de maneira consolidada, decidido que a atribuição da responsabilidade civil deve recair de maneira solidária e integral sobre qualquer daqueles que tenham, de algum modo, contribuído para a ocorrência do dano ambiental (BENJAMIN, 1998; CRUZ, 1997; LEITE; AYALA, 2010; LUCARELLI, 1994; PERALES, 1993; STEIGLEDER, 2017).

A solidariedade apresenta sustentação normativa, como acima enfrentado, e justificativa para uma política de proteção ambiental num Estado de Direito, a partir da necessidade de estimular e incentivar monitoramento mútuo dos potenciais poluidores (FAURE, 2009). Na maior parte dos casos, a solidariedade apresenta uma melhor solução, se comparada com

3 A título de exemplo de precedentes do STJ, ver Brasil (2009b; 2010). 
a responsabilidade compartilhada, para o problema probatório inerente a danos cumulativos, continuados e progressivos. Por essa razão, não é de se estranhar que a maioria dos sistemas nacionais, comunitários e internacionais adotem a responsabilidade solidária para danos ambientais. No entanto, "se esta não é aplicada em justos limites, pode provocar situações verdadeiramente injustas” (CATALÁ, 1998, p. 190). Em nível geral, sob o socorro das lições de Kenneth S. Abraham, a solidariedade aplica-se para três principais casos. O primeiro, para casos em que há uma atuação conjunta de agentes causadores do dano (joint tortfeasors). Além deste, há a incidência da responsabilidade solidária aos casos de agentes independentes, porém responsáveis por um mesmo e indivisível dano. O terceiro exemplo trata-se de um desvio deste último. Como explica o autor, tal indivisibilidade do dano pode ser teórica, quando a natureza do dano impossibilita sua divisibilidade (segundo exemplo), ou pragmática, quando, apesar de o dano ser passível de divisibilidade, essa prova não foi possível ou realizada pelo réu (terceiro exemplo) (ABRAHAM, 2012).

\subsection{A solidariedade e o litisconsórcio passivo facultativo}

Outro aspecto constantemente utilizado para a aplicação da solidariedade dos corresponsáveis pelo dano ambiental consiste na configuração constitucional do meio ambiente como bem de uso comum do povo (res omnium) que, nessa condição, é corretamente compreendido como uma "unidade infragmentável" (BENJAMIN, 1998). No entanto, há uma constante atribuição de que, em virtude dessa condição de bem de uso comum, as lesões a esses bens seriam sempre indivisíveis. Para esse entendimento, sendo o meio ambiente como um objeto unitário (bem de uso comum do povo), concluir-se-ia, consequentemente, indivisível dano ambiental coletivo, justificando a imputação da responsabilidade civil in solidum a todos aqueles que, direta ou indiretamente (art. $3^{\circ}$, IV, da Lei n. 6.938/81), contribuíram para a ocorrência do dano ambiental. Não parece, contudo, correto pressupor que todo e qualquer dano ambiental seja sempre indivisível, apesar de o bem ambiental o ser, conceitualmente. Embora o ambiente seja uma unidade infragmentável, existem degradações ambientais cuja contribuição por diversos autores poderá vir a ser passível de fragmentação (divisível) ou não.

Em decorrência do frequente entendimento de que os danos ambientais seriam sempre marcados por uma indivisibilidade em seus múltiplos 
elementos constitutivos e da frequente impossibilidade de sua fragmentação em suas cadeias causais, a responsabilidade solidária vem sendo aplicada no sistema jurídico brasileiro, sem maiores avaliações acerca da possibilidade de fragmentação em parcelas de um dado dano ambiental. Assim, em face das relações de exploração e intervenção sobre os bens ambientais, e diante da constatação da pluralidade de agentes ou da multiplicidade de fontes na ocorrência de um dano ambiental, os tribunais têm imposto, de maneira generalizada, a solidariedade passiva a todos aqueles que tenham contribuído, direta ou indiretamente, para a lesão ambiental. Isso tem ocorrido sem maiores reflexões acerca dos critérios legais e interpretativos que envolvem as especificidades dos danos ambientais em casos específicos. Parece necessário, nesse sentido, um maior aprofundamento, a fim de evitar a imputação injusta e desproporcional de custos a terceiros para a remediação ambiental de áreas degradadas.

A fim de sustentar o entendimento majoritário, no sentido de que um dano ambiental sempre repercute em solidariedade em virtude da indivisibilidade do bem ambiental, faz-se uso do próprio conceito normativo de poluidor, consignado no art. $3^{\circ}$, IV, da Lei n. 6.938/81. A partir de tal dispositivo, há o entendimento consolidado de que "a ação por dano causado ao meio ambiente pode ser proposta contra o responsável direto ou indireto, ou contra ambos, em face da responsabilidade solidária pelo dano ambiental" (BRASIL, 2009a). Assim, em matéria ambiental todos aqueles que tenham participado de maneira direta ou mesmo indiretamente da ocorrência de alguma degradação ambiental, poderão vir a ser responsabilizados. Em outras tintas, tanto os responsáveis diretos como os indiretos podem vir a ser responsabilizados pelos danos ambientais decorrentes de suas atividades, quer comissivas ou omissivas.

O Superior Tribunal de Justiça (STJ) vem aplicando a responsabilidade solidária entre todas as causas e agentes que contribuíram para a ocorrência de um dano ambiental (BRASIL, 1995). Os julgados mais recentes, têm mantido o entendimento, conforme didaticamente ementado no acórdão do REsp 843.978/SP (BRASIL, 2013). Nota-se pelo próprio conteúdo desse julgado que, bem sintetiza o entendimento vigente, a solidariedade aplicada em matéria ambiental (direito material) acaba por levar à aplicação do litisconsórcio facultativo (direito processual) aos casos de ações para reparação de danos ambientais contra múltiplos agentes. Isto se dá em razão de ser o direito material que determina a existência ou não de uma "comunhão de direitos ou obrigações" (art. 113, I, do Código de Processo 
Civil) que, por seu turno, levará à configuração de um litisconsórcio facultativo. Portanto, nos casos de solidariedade, há sempre a comunhão quer entre credores ou devedores solidários (NERY JUNIOR; ANDRADE NERY, 2014). Sob o ponto de vista normativo, tem-se uma relação entre o disposto no art. 113, I, e a solidariedade referente ao dano ambiental (art. $3^{\circ}$, IV, da Lei n. 6.938/81, e art. 942 do Código Civil). Este vem sendo o entendimento consolidado do STJ.

Para compreendermos essa relação entre solidariedade e litisconsórcio facultativo, é fundamental retomarmos o conteúdo da própria descrição clássica das obrigações solidárias. Segundo a clássica doutrina de Direito das Obrigações, essas relações apresentam uma dupla dimensão das relações jurídicas, uma externa (do credor com os coobrigados) e outra interna (dos coobrigados entre si). Para tanto, no caso da solidariedade passiva, esta "só se manifesta nas relações externas, isto é, as que se travam entre [...] coobrigados e o credor" (GOMES, 1996, p. 61). Externamente, “o credor tem direito a exigir e receber de qualquer dos devedores a dívida comum. [...] Cabe a escolha ao credor" (GOMES, 1996, p. 66). Em síntese, o titular do direito tem a prerrogativa de cobrar, a sua escolha, de qualquer dos coobrigados solidários, o valor integral da dívida. A figura abaixo traz a representação gráfica dessas relações solidárias.

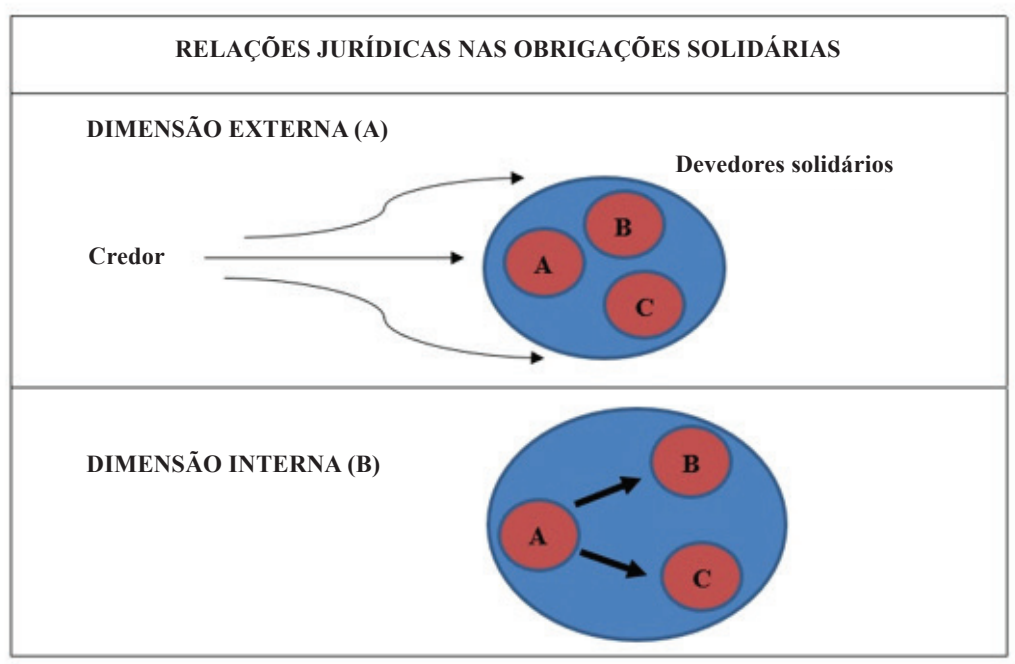

Figura 1. Representação gráfica das dimensões externa (imagem A) e interna (imagem B) nas relações jurídicas envolvendo obrigações solidárias.

Fonte: elaboração própria. 
Do mesmo modo, a solidariedade existente no Direito Ambiental vem sendo aplicada, marcadamente, em razão destes dois fatores: (i) pluralidade de agentes; e (ii) indivisibilidade do dano (face a uma compreensão de unidade "indivisível" do bem ambiental, conforme já enfrentado acima). A pluralidade de causas e de agentes, que envolvem determinado dano ambiental, apresentam, também, uma dimensão externa e uma dimensão interna. Há a vinculação entre os agentes causadores da lesão e suas responsabilidades ante o dano ambiental cometido conjuntamente, podendo ser acionado um ou vários agentes, "à escolha do credor". No caso de danos ambientais coletivos, não se trata precisamente de um "credor" propriamente dito, mas de um legitimado processual (por se tratar de tutela de interesses transindividuais, nos termos do art. $5^{\circ}$ da Lei n. 7.347/85). Em outras palavras, sob a perspectiva de uma dimensão externa (dos agentes diante da sociedade), todos os corresponsáveis podem vir a responder, individualmente, pela integralidade do dano ambiental. Aqui, a formação da "comunhão de direitos ou de obrigações relativamente à lide" prevista no art. 113, I, do Código de Processo Civil, é ditado pelo direito material (BRASIL, 2002). Sendo o caso de obrigações solidárias, tem o credor ou o legitimado processual a disponibilidade de escolher ajuizar a demanda contra um ou vários dos corresponsáveis. Portanto, a aplicação do litisconsórcio facultativo em matéria de danos ambientais coletivos decorre da compreensão generalizada de indivisibilidade do dano dessa espécie e, por consequência, da solidariedade dos agentes. Cumpre recordar que a função do litisconsórcio facultativo é sua utilidade prática e facilitação à posição do autor (credor ou legitimado processual). Assim, enquanto para este o julgamento do mérito da demanda não depende de sua formação, para o litisconsórcio necessário a cumulação subjetiva das partes (ativa ou passiva) é condição de admissibilidade ao julgamento da demanda. Isto é, sem ela o processo deve ser extinto sem resolução de mérito (art. 485, VI, Código de Processo Civil).

Na dimensão interna da solidariedade, aquele que paga a integralidade correspondente à recuperação do dano ambiental tem o direito regressivo contra os demais, havendo uma presunção de "igualdade de quotas" no que respeita à obligatio dos corresponsáveis (GOMES, 1996, p. 66). Contudo, na dimensão interna da solidariedade, caso o referido dano ambiental venha ser passível de fracionamento proporcional a cada uma das condutas 
dos responsáveis, aquele que honrou com a reparação integral do dano pode se ressarcir, em ação de regresso autônoma contra os demais, proporcionalmente à participação de cada um. ${ }^{4}$

\section{EXCEÇÕES À SOLIDARIEDADE E AO LITISCONSÓRCIO FACULTATIVO EM CASOS DE PLURALIDADE DE AGENTES}

\subsection{A divisibilidade do dano ambiental}

Preliminarmente, importante uma brevíssima reflexão acerca das distinções entre os conceitos de obrigações divisíveis, indivisíveis e solidárias (GOMES, 1996). Enquanto as duas primeiras são classificadas quanto ao objeto da prestação, a solidariedade tem sua classificação centrada nos sujeitos (GOMES, 1996). As obrigações divisíveis consistem naquelas prestações que podem ser fracionadas, enquanto a indivisibilidade não encontra essa possibilidade.

As obrigações indivisíveis têm apenas uma semelhança com a solidariedade, em ambas o credor poderá exigir dos devedores a integralidade da prestação, mas terminam aí as afinidades (FARIAS; ROSENVALD, 2012, p. 305). De outro lado, apesar de ambos os conceitos (indivisível e solidário) afastarem a aplicação do princípio da divisibilidade (regra geral das obrigações), no caso das obrigações indivisíveis é a natureza da obrigação que impede a repartição obrigacional em tantas frações quantas sejam o número de sujeitos, enquanto que na solidariedade é a vontade das partes ou a disposição de lei que impede a imposição dessa divisão (COELHO, 2012). A solidariedade não se presume, devendo decorrer de lei ou da vontade das partes (art. 265 do Código Civil).

Assim, apesar da inegável existência de conexões comuns entre a invisibilidade e a solidariedade, estas não estão necessariamente atreladas uma à outra. Pode, contudo, ser dito que a indivisibilidade do objeto da prestação não é motivo imediato para a imposição imediata de solidariedade, mas, de outro lado, a constatação de divisibilidade do objeto desta, necessariamente, será motivo para o afastamento da solidariedade, por evidente. Tanto é, que a divisibilidade é a regra geral nas prestações obrigacionais civis (art. 257 do Código Civil), sendo a indivisibilidade (art. 259 do Código Civil) e a solidariedade (art. 264 do Código Civil), exceções

4 Nesse sentido, ver Brasil (2000). 
(FARIAS; ROSENVALD, 2012). Pela proximidade conceitual entre a indivisibilidade e a solidariedade, constituídas conceitualmente em frontal oposição à divisibilidade, nada impede que se reúnam na mesma obrigação as qualidades da indivisibilidade e da solidariedade. Nesse sentido, Orlando Gomes chega a dizer que "não há dificuldade em resolver as situações oriundas de obrigações com prestação indivisível, desde que se reconheça a necessidade de discipliná-las pelas normas relativas às obrigações solidárias" (GOMES, 1996, p. 74-75).

A título de conclusão parcial do acima enfrentado, deve-se constatar que tanto a doutrina quanto a jurisprudência brasileira vêm atribuindo, de modo generalizado, a indivisibilidade como uma característica inerente aos danos ambientais. De tal maneira, olvida-se, assim, o fato de alguns danos ambientais serem, técnica e cientificamente, divisíveis. Isto é, são passíveis de uma fragmentação quanto à participação causal dos agentes envolvidos em frações determináveis.

Aqui, exemplifica-se o caso de uma disposição irregular de resíduos industriais em determinada área por diversos agentes, contaminando-a. Considerando que as várias fontes geradoras desse dano sejam passíveis de identificação pela existência de seus produtos no local, tem-se a possível determinação dos percentuais de participação de cada uma das fontes ou, no mínimo, a atribuição de seu segmento mercadológico. No mesmo sentido, um caso de disposição irregular de produtos químicos, por diversas empresas, em determinada área, contaminando-a. Para ambos os casos, em havendo a capacidade científica de determinação da participação de cada empresa, quer em virtude da divisibilidade da área (fontes identificadas em áreas diferentes) ou dos fatores de degradação (resíduos ou agentes passíveis de diferenciação), ter-se-á um caso emblemático de dano ambiental divisível. Em síntese, sempre que for possível tecnicamente a determinação da fragmentação do dano nos percentuais de cada uma das fontes geradoras e suas consequentes contaminações, ter-se-á um dano divisível (FARBER; FREEMAN; CARLSON, 2014). Como consequência jurídica, quando divisível, cada um dos responsáveis estaria obrigado a reparar apenas suas parcelas de contribuição, naquilo que se denomina, responsabilidade compartilhada ou coletiva, como visto acima. De outro lado, sempre que houver indeterminação haverá solidariedade.

Importante destacar que a divisibilidade de um dano ambiental não é novidade no Direito Ambiental Internacional. Nesse sentido, a Convenção sobre Responsabilidade Civil por Dano Resultante de Atividades 
Perigosas, firmada em Lugano em 1993, pelo Conselho da Europa prevê a possibilidade do explorador liberar-se da responsabilidade solidária se este é capaz de demonstrar que, com sua atividade, contribuiu tão somente para uma parte específica do dano que lhe é imputado (art. $6^{\circ}$, item 3 ). Nesses casos, o responsável estaria obrigado apenas pelos percentuais ou áreas que lhe dissessem respeito.

A divisibilidade é, portanto, motivo para a fragmentação do dano entre seus respectivos responsáveis, permitindo uma maior justiça e eficiência ao sistema de responsabilidade civil. Fala-se em justiça pois, do contrário, mesmo aquele que tenha contribuído em percentual bem definido e cuja responsabilidade seja parcial pelo dano, em caso de responsabilidade solidária, este poderá ser (injustamente) responsabilizado pelo todo, estimulando comportamentos irresponsáveis dos demais agentes envolvidos (via de regra de pequeno e médio porte). Crítico a esse entendimento da Convenção de Lugano, Martin (1994) entende que a referência à divisibilidade do dano contribuiria para a constituição do que ele chama de uma "falsa solidariedade". No entanto, inegável que a solidariedade se aplicada sem o devido equilíbrio e limites bem definidos, acarreta verdadeiras injustiças, estimulando condutas irresponsáveis ambientalmente.

A consequência processual direta da adoção desse entendimento, aqui defendido, consistirá na alteração do regime de litisconsórcio aplicado ao caso. Senão vejamos. Em casos de possível fragmentação ou divisibilidade do dano ambiental, estar-se-ia diante da possibilidade de litisconsórcio necessário (arts. 114 e 115, parágrafo único, do Código de Processo Civil), devendo ser trazidos aos autos todos os partícipes conhecidos.

Essa posição mostra-se, ao nosso ver, mais justa, pois visa combater o risco moral de estimular comportamentos irresponsáveis de médias e pequenas empresas que, seguras da condição econômica de empresas maiores envolvidas, são estimuladas pela solidariedade a agirem irresponsavelmente, certas de que o foco judicial recairá sobre aquelas que, muitas vezes, detém maior poder econômico, apesar de participarem de percentuais menores do dano ou de terem maiores compromissos com segurança ambiental. Não raras vezes, em um sistema de responsabilidade solidária, as empresas que acabam respondendo efetivamente por danos ambientais são aquelas que detém maior capacidade financeira, embora demonstrem um maior rigor no cumprimento da norma ambiental (CATALÁ, 1998).

É nesse sentido que o direito comparado apresenta interessantes soluções, na busca de maior equilíbrio e equidade. No direito norte americano, 
v.g., a section 107 da Comprehensive Environmental Response, Compensation, and Liability Act (CERCLA), também conhecida como "superfund", estabelece um número bastante grande de partes que podem ser responsáveis, desde o proprietário até pessoas que, no passado, depositaram lixo ou substâncias perigosas no local (FARBER; FINDLEY, 2010). O objeto de tal legislação é estabelecer a facilitação e os critérios para a responsabilização civil pela limpeza de locais contaminados por produtos químicos tóxicos. A partir dessa legislação, o governo pode cobrar os custos da limpeza de áreas contaminadas desses atores (CASTRO; REZENDE, 2015).

Em linhas gerais, a configuração da divisibilidade ou indivisibilidade de determinado dano ambiental é critério internacional para servir como elemento definidor de qual o sistema de responsabilidade será aplicado. Se o dano for indivisível, estar-se-á diante de um caso de responsabilidade solidária (joint and several liability), mas caso o dano seja passível de divisão, aí estar-se-ia sob a incidência da responsabilidade compartilhada (several liability). A consequência prática (e processual) disso é de que, nesse caso, o autor deverá necessariamente acionar todos os envolvidos, podendo cobrar apenas os percentuais afetos a cada uma das parcelas do dano divisível. Já no caso de danos indivisíveis, a solidariedade permite que o autor (governo) acione qualquer dos corresponsáveis previstos na legislação (CERCLA). Os tribunais norte americanos têm sustentado que, em casos de danos ambientais em que se tenha um "dano indivisível", há a solidariedade (joint and several liability) entre as partes responsáveis, com todas respondendo pelo prejuízo, isolada ou conjuntamente. Uma exceção a essa regra da solidariedade é quando um dos responsáveis é capaz de provar que a lesão causada é divisível, havendo, nesses casos, a necessidade de inclusão na ação de todos os responsáveis em suas quotas-parte. Nessa direção fazem-se os precedentes United States v. Monsanto Co., 858 F.2d 160 (4th. Circ. 1988) e United States v. Chem-Dyne Corp., 572 F. Supp. 802 (S.D. Ohio).

Neste último, a Corte afirmou:

Caso o dano seja divisível e houver uma base razoável para rateio dos danos, cada um dos réus é responsável apenas pela porção do dano causado por este [...]. Nesta situação, o ônus da prova quanto à repartição cabe a cada réu [...]. De outro lado, se os réus causaram um dano inteiramente indivisível, cada um é sujeito à responsabilidade pelo dano inteiro (UNITED STATES, 1988) (tradução livre).

Por evidente, o ônus da prova acerca da "divisibilidade" do dano ambiental por contaminação recai sobre o acusado, para limitar sua 
responsabilidade (FARBER; FINDLEY, 2010). Em tais casos, os demandantes apenas poderão cobrar daqueles acionados na demanda judicial, e na medida da participação de cada um. Ao passo que a regra em matéria de contaminação tóxica é da responsabilidade ser objetiva e solidária, a exceção pela divisibilidade decorre do princípio da common law de que cada um deve ser responsabilizado pelo percentual de sua participação e culpabilidade, numa representação do próprio Princípio do Poluidor-Pagador (GREENBERG, 2018). Essa divisibilidade configurase em casos em que a contaminação está geograficamente separada ou os múltiplos operadores atuaram em períodos temporais diversos e bem definidos - combinação de fatores geográficos, temporais e volumétrico/ toxicidade (GREENBERG, 2018).

Antes que se diga que isto acarretaria a não remediação de "parcelas órfãs" (prejudicando o direito fundamental de todos ao meio ambiente ecologicamente), tem-se importantes exemplos do direito norte americano, ao nosso ver, absolutamente compatíveis com o nosso sistema. Primeiro, se algum dos poluidores for identificado apenas após o ajuizamento da ação, pode-se tanto inclú́-lo no feito ou promover uma ação individualizada em sua parcela contributiva. Ainda, um fator complicador para a obtenção da reparabilidade do dano ambiental pode ser a insolvência ou indisponibilidade de um potencial responsável. Para tanto, há no direito norte americano importante solução para a manutenção de "fatores equitativos" aos agentes responsáveis pelo dano ambiental, segundo a qual, em se tratando de uma contaminação passível de divisibilidade, os percentuais "órfãos" (decorrentes da insolvência ou desaparecimento de um ou mais responsáveis) deverão ser rateados pelos demais responsáveis em suas respectivas proporções. Assim dispôs decisão do $9^{\circ}$ Circuito, segundo a qual "os custos das parcelas órfãs são distribuídos equitativamente entre todos os potenciais responsáveis assim como se dá no caso de custos de limpeza de áreas contaminadas" (UNITED STATES, 1997, tradução livre). Este consiste em um modelo híbrido, em que a responsabilidade compartilhada se justifica pela divisibilidade, mas em havendo insolvência ou dissipação de uma das partes, seu percentual é redistribuído proporcionalmente entre os demais, mantendo-se justiça e equidade.

No Direito norte americano, especificamente na CERCLA, caso o dano seja divisível, o governo ou um corresponsável (em nível de direito de regresso) deve acionar todos os demais responsáveis. Nesses casos, cada parte poderá ser responsabilizada apenas em sua parcela. Trata-se de 
exceção à regra geral que aplica a responsabilidade solidária (joint and several liability), passando, nesses casos, a ser aplicada a responsabilidade compartilhada ou coletiva (several liability).

De outro lado, no Direito Ambiental brasileiro, vem sendo aplicada a regra da solidariedade a todos aqueles que, de algum modo, colaboraram para a ocorrência de um dano ambiental, sem qualquer avaliação da divisibilidade ou não do dano ambiental in casu. Considerando ser o direito material quem determina a existência de comunhão de direitos ou obrigações e que, nesses casos, o credor ou o legitimado processual podem cobrar o valor integral de um ou vários réus, à sua escolha, tem-se a incidência de litisconsórcio facultativo à matéria em questão. Em nível de prognóstico, com a ampliação do conhecimento científico e consequente rastreabilidade dos produtos contaminantes, há uma tendência futura de surgimento de debates acerca da inadequação da solidariedade ambiental para casos de danos divisiveis, nos quais é possível determinar o percentual de contribuição de cada um dos agentes para a realização do dano ambiental.

$\mathrm{Na}$ atualidade, a matéria vem dispensando a análise desses elementos, aplicando-se de maneira consolidada a solidariedade por dano indivisível a todos os casos, mesmo para aqueles em que é possível a demonstração da divisibilidade do dano. Contudo, a capacidade técnica para descrição e o conhecimento antecipado acerca dos percentuais de participação de cada um dos agentes de um dado dano ambiental, podem refletir a necessidade de mudança no hoje consolidado entendimento de aplicação do litisconsórcio facultativo a todos os casos de danos ambientais. Essa mudança aponta na direção da necessidade de o autor arrolar todos os partícipes conhecidos e identificados, sempre que o dano for divisível ou fragmentável (litisconsórcio necessário). Entendimento este que privilegia a eficiência e a equidade, pois favorece o arrolamento do maior número de responsáveis no feito judicial, reduzindo os riscos de inadimplemento e ineficácia da medida jurisdicional. Do contrário, a aplicação generalizada e irrestrita da responsabilidade solidária acaba provocando uma sobrecarga secundária do judiciário, em nível de direitos regressivos, com mais tempo para dissipação de patrimônio e insolvências dos demais corresponsáveis (não acionados de imediato). Assim, em casos de divisibilidade comprovada de um dano ambiental, o ônus da prova desta (divisibilidade do dano) é, por evidente, da(s) parte(s) demandada(s), devendo haver a inclusão de todos os agentes. Lembre-se que, caso um agente que contribui em um dano divisível, após ser incluído, tenha problemas em honrar com seu percentual, 
esse percentual "órfão" será redistribuído proporcionalmente entre os demais, num formato híbrido da responsabilidade compartilhada.

\subsection{Aplicação do litisconsórcio necessário para casos em que o cumprimento das obrigações dependa ou venha a afetar as atividades ou os patrimônios de terceiros}

Não obstante a regra geral de que os responsáveis por uma degradação ambiental sejam coobrigados solidários, com a formação de litisconsórcio facultativo, existem exceções. Em conformidade com o conteúdo acima demonstrado, casos passíveis de divisibilidade do dano ambiental demandam por responsabilidade compartilhada e, consequentemente, litisconsórcio necessário. Nesse caso, como visto, seria de exceção ao caráter facultativo do litisconsórcio. Outro exemplo de exceção ao litisconsórcio facultativo em matéria de dano ambiental, consiste nos casos em que determinada decisão de responsabilidade civil ambiental necessariamente afetará a "esfera jurídico-patrimonial de terceiros, quando, então, se impõe a formação de litisconsórcio passivo necessário" (MILARÉ, 2015, p. 441).

Trata-se de casos em que "a decisão impõe obrigação a terceiro que não compõe o polo passivo da ação", sendo aplicável "a regra do litisconsórcio passivo necessário, para que não reste violado o contraditório e a ampla defesa" (FREITAS; CARDOSO, 2017, p. 182). Esse entendimento de aplicação de litisconsórcio necessário a casos pontuais em que a eficácia da decisão judicial dependa necessariamente de terceiros, encontra precedentes jurisdicionais, conforme demonstra sólida corrente no STJ (BRASIL, 2009c; 2014).

Nesse sentido, cita-se o REsp 843.978/SP, de ação contra os loteadores em caso de loteamento clandestino em que os adquirentes possuidores estão, de mão própria, alterando a situação física do imóvel, promovendo degradação ambiental. O julgado define que, apesar da regra geral de solidariedade e litisconsórcio facultativo em casos de danos ambientais,

[...] como única forma de garantir plena utilidade à prestação jurisdicional, impõe-se o litisconsórcio necessário entre o loteador e o adquirente se este, por mão própria, altera a situação física ou realiza obras no lote que, ao final, precisarão ser demolidas ou removidas (BRASIL, 2013).

Em síntese, nesses casos há a imposição de litisconsórcio pois as providências requeridas na demanda judicial irão afetar e dependerão 
necessariamente de terceiros não incluídos na demanda. Assim, esses terceiros devem ser necessariamente incluídos na demanda sob pena de violação do direito fundamental ao devido processo legal, nos termos do art. 5, LIV, da Constituição Federal (FREITAS; CARDOSO, 2017). A premência de intervenção no patrimônio material e jurídico de terceiros acarreta também um deslocamento da incidência da matriz da solidariedade para a responsabilidade compartilhada, com cada um dos partícipes sendo responsável por sua esfera de participação na conduta necessária. Importante o resguardo, pela inclusão necessária dos terceiros no polo passivo do feito, uma vez que, do contrário, estar-se-á colocando em risco de ofensa aos princípios constitucionais do devido processo legal, do contraditório e da ampla defesa (DANTAS, 2010).

Esse também é o caso em que uma ordem de demolição seja direcionada a qualquer entidade diversa dos atuais proprietários ou terceiros de boa-fé. A título exemplificativo, tem-se o caso de ajuizamento de uma ação civil pública com pedido de demolição contra a construtora, ignorando a existência de proprietários das residências e da constituição de um condomínio. Diante desse caso, há a necessidade de formação do litisconsórcio necessário com todos aqueles que tiverem seu patrimônio atingido pela possível decisão judicial, sob pena de invalidade dos atos processual por violação às garantias constitucionais da ampla defesa, contraditório (art. $5^{\circ}, \mathrm{LV}$, da Constituição Federal) e devido processo legal (art. $5^{\circ}$, LIV, da Constituição Federal).

\subsection{Contribuições insignificantes}

Outro motivo possível de afastamento da responsabilidade solidária e, mais que isto, de ausência de responsabilidade civil de uma parte ocorre quando, comprovadamente, esta tenha produzido contribuições insignificantes ao resultado lesivo. Por evidente, a grande dificuldade prática é delimitar critérios para determinar que a contribuição realmente seria insignificante e insuficiente para ocasionar o dano configurado e objeto de análise judicial. Nesses casos, ocorre que "provavelmente, a "porção do dano' que lhe corresponde não alcance nem sequer o grau necessário para ser considerado um dano suscetível de reparação" (CATALÁ, 1998, p. 192).

Cumpre esclarecer que a reflexão sobre as contribuições insignificantes se encontra abrangida pela matéria inerente à causalidade cumulativa, sob a denominação específica de minimale Kausalität (causalidade mínima) 
(GONZÁLES, 2005). Esse conceito configura-se quando determinado dano decorre da soma de um número incontável de contribuições causais. Porém, se consideradas individualmente, essas atividades não apenas são permitidas (lícitas) como sua contribuição, isoladamente considerada, é tão pequena que se torna irrelevante para a ocorrência do fenômeno lesivo. Exemplo desses casos seriam as emissões dos veículos automotores derivados da queima de combustíveis fósseis.

A matéria é tormentosa para doutrina em direito comparado e muito pouco, ou quase nada, debatida em nível nacional. Duas soluções aparecem. De um lado, admitir que haja a responsabilização, mesmo que difícil estabelecer sua causalidade em razão do número excessivo de agentes contaminantes e contribuições individuais, demasiadamente pequenas. Para esse entendimento, aplicar-se-ia a responsabilidade solidária ou uma responsabilidade compartilhada por cotas -iguais em caso de dúvida (GONZÁLES, 2005). De outro lado, para aqueles que entendem que não deve haver a responsabilização em casos de contribuições insignificantes, defende-se ser demasiadamente alto o custo econômico para efetivar essa responsabilização (transaction costs), uma vez que para determinar os autores e suas cotas haveria a necessidade de mecanismos de controle demasiadamente caros e, por essa razão, desproporcionais em relação aos benefícios decorrentes do litígio (GONZÁLES, 2005).

Assim, parece evidentemente injusta a responsabilização solidária de partes que contribuíram de maneira insignificante para o dano global. Do mesmo modo, ineficiente e desproporcional a responsabilização de contribuições insignificantes, por quotas isoladamente. Tanto que, até o presente momento, não existem ações que tentem responsabilizar solidariamente os proprietários de automóveis no mundo. Porém, de outro lado, também parece inadequado exonerar completamente os grupos que tenham contribuído para tais danos difusos. Nesse sentido, a título exemplificativo, existem demandas em nível de litigância climática contra montadoras em virtude dos danos decorrentes de seus produtos. Uma alternativa, mais promissora, consiste em internalizar os danos difusos por meio de obrigações antecipadas (ex ante) ou ex post consistentes na contribuição para fundos financeiros. Essas obrigações de contribuições decorreriam do fato de estes pertencerem a determinados grupos ou categorias, v.g., os proprietários de veículos automotores, sendo que a medida de contribuição poderia, por exemplo, depender da quota anual percorrida em quilometragem no exercício de um ano (GONZÁLES, 2005). Para tais casos (de poluição 
atmosférica e contribuição para o aquecimento global), o mais promissor seria compor tais fundos com valores oriundos de empresas do segmento mercadológico do qual decorreu a contribuição para as mudanças climáticas, em detrimento dos sujeitos individuais. A definição dos percentuais de cada empresa dar-se-ia proporcionalmente à parcela de mercado que esta ocupa (Market Share Liability).

\section{O PROBLEMA DO POLUIDOR INDIRETO}

A regra geral em sede de responsabilidade civil é "que cada um responda por seus próprios atos", naquilo que se denomina responsabilidade direta ou por fato próprio (CAVALIERI FILHO, 2012, p. 204). De maneira excepcional, contudo, o direito civil prevê a possibilidade de uma pessoa poder vir a responder pelo fato de outrem, nominada de responsabilidade indireta ou por fato de outrem. Esses casos, contudo, não podem se dar de maneira "arbitrária e indiscriminada", limitando-se aos casos previstos no art. 932 do Código Civil, cujo conteúdo prevê os casos taxativos de pessoas que, por seu dever de guarda ou vigilância, serão responsabilizadas por fato de outrem. Destarte, em matéria de responsabilidade civil geral por fato de outrem, quando alheia a configuração de qualquer nexo causal, o direito privado lançou mão da técnica de "canalização", atribuindo responsabilidade para pessoas que, apesar de não terem contribuído diretamente para a lesão, são responsabilizadas em virtude de seu dever de guarda, vigilância ou cuidado. Note-se novamente que tais previsões, no direito privado, estão estabelecidas taxativamente no rol do art. 932 do Código Civil.

Em matéria ambiental, como já visto, a imposição da solidariedade encontra sua fundamentação num conjunto de condutas que tenham dado azo a um dano ambiental, quer por uma ação lesiva ou pela violação a um dever de guarda, vigilância ou cuidado, sintetizado, na expressão de dever de segurança ambiental. Portanto, em matéria ambiental os critérios para a definição da solidariedade e da responsabilidade civil do indireto estão mais afetas à interpretação oriunda da análise conjunta do art. 942 do Código Civil com o art. $3^{\circ}$, IV, da Lei n. 6.938/81.

Como bem observado por Antunes (2016, p. 562), “[a] definição de poluidor indireto é um dos temas mais controversos do Direito Ambiental brasileiro e, seguramente, não há consenso doutrinário ou jurisprudencial quanto à extensão do conceito". Em estudo sobre o tema, Rômulo Sampaio 
constata que "ao recepcionar a figura do poluidor indireto, o art. $3^{\circ}$, IV, da Lei n. 6.938/81, não o definiu. Trata-se, portanto, de um conceito jurídico indeterminado" (SAMPAIO, 2013, p. 147). O preenchimento desse conceito deve, portanto, atentar para o caráter de contribuição dos agentes envolvidos. Conclusão imediata desse raciocínio é de que a solidariedade ambiental, contudo, não elide a necessária demonstração de nexo causal das causas e concausas para ocorrência do dano. Dito de outra maneira, para caracterização da solidariedade deve ser demonstrada a conduta (ativa ou omissiva) "concorrente" para a configuração do dano ou para o agravamento deste. Trata-se da causalidade plural comum. O fundamento, portanto, da solidariedade se dá em virtude do fato de que as diversas condutas (ativas ou omissivas) "dão origem ao resultado" (CAVALIERI FILHO, 2012).

Mesmo em casos sob a incidência da responsabilidade objetiva, há a necessidade de identificação do nexo causal, como relação de causa e consequência, em nível probatório. Assim como o cerne da responsabilidade subjetiva é a conduta culposa, em sua matriz objetiva, o foco de análise jurídica é sempre o nexo de causalidade. Portanto, este segue sendo exigido para casos de múltiplos agentes.

Deve-se ter em mente que um dano ambiental pode ter múltiplas fontes e causas, podendo ser essas fontes diretas ou indiretas. Como enfrentado anteriormente, a solidariedade consiste em processo de expansão dos limites dos potenciais responsáveis por um dano ambiental. A favor de sua aplicação, quando e se feita com equilíbrio, esta "oferece excelentes incentivos ex ante para monitoramento mútuo entre potenciais poluidores" (FAURE, 2009, p. 259). Tudo isto antes mesmo de qualquer degradação ambiental. Dependendo dos limites e critérios utilizados para sustentar essa expansão, ter-se-á uma resposta ao nível ótimo de internalização das externalidades ou, de outro lado, em caso de uma expansão exagerada, haverá uma sobrecarga injusta sobre as atividades econômicas, afetando o desejável equilíbrio nas relações jurídicas, ecológicas e econômicas. Se, de um lado, é desejável maximização dos processos de remediação de danos ambientais pelo Direito e sua imputação àqueles que contribuíram para esses resultados danosos, por outro, a delimitação de quem é responsável deve ser justa e proporcional. Um sistema demasiadamente amplo tende a transferir responsabilidades para terceiros, podendo ocasionar o indesejável efeito colateral secundário: a irresponsabilidade de poluidores diretos e a responsabilização de terceiros, mesmo que estes não tivessem 
conhecimento, deveres legais expressos ou condições de evitar a ocorrência dos danos ambientais em questão.

Por essa razão é tão relevante adotar critérios de definição e limitação das fronteiras da solidariedade em sua função de expansão da responsabilidade civil, evitando que aqueles sujeitos que tenham contribuído deixem de ser responsabilizados pelos danos perpetrados. Se de um lado a solidariedade é uma solução encontrada internacional e nacionalmente para casos de pluralidade causal, esta também apresenta sérios riscos de uma dissuasão excessiva (over deterrence). Uma interpretação demasiadamente extensiva pode gerar efeitos colaterais secundários (que, inclusive, podem ser nefastos para a própria proteção ambiental).

Apesar de pouco ventilado em contexto nacional, as possíveis consequências negativas da solidariedade foram e são constantemente debatidas em nível de direito comparado. Não é porque se adota a responsabilidade solidária em um sistema jurídico que não se deve refletir intensamente sobre sua abrangência e seus limites, a fim de evitar efeitos colaterais, dissuasão excessiva e injustiças.

A solidariedade, como adverte Michael Faure, pode ensejar a violação do princípio básico da justa e eficiente compensação, o qual prevê que um agente deve ser responsabilizado, em princípio, a compensar somente na medida e proporção de sua contribuição para as perdas (BERGKAMP, 2001; FAURE, 2009). O autor ainda destaca que a dimensão dos efeitos colaterais depende do regime legal escolhido e da solvência ou não dos agentes envolvidos. Não raras vezes, aquele corresponsável acionado, mesmo que determinável sua parcela de responsabilização ou mínima, vêse responsabilizado pelo custo total do dano pela dissipação (insolvência) dos demais corresponsáveis. Assim, este é responsabilizado por parcelas e danos não ocasionados por sua atividade (FAURE, 2009).

Ainda, a solidariedade tende a estimular o efeito "deep pocket", conhecido como o risco da vítima ou legitimados se dirigirem à parte que possua mais recursos e capacidade financeira, em detrimento da parte que tenha produzido a maior contribuição para a ocorrência do dano. Pode, assim, haver o desvirtuamento indesejado do Princípio do Poluidor Pagador (maior aplicação em nível regulatório) e do Princípio da Responsabilização (aplicação das responsabilidades civil, administrativa e criminal em matéria ambiental). Esse foco na responsabilização das empresas por seu porte econômico apresenta um paradoxo e risco moral. Ao se penalizar empresas por suas maiores condições financeiras, pode-se estar punindo 
aquelas que também estejam sendo as que mais cumprem a normativa ambiental, "salvando", assim, aquelas de menor porte, ambientalmente débeis e com tecnologias mais sucateadas, e que, por isso, oferecem menor segurança ambiental (CATALÁ, 1998). Uma demasiada amplitude e extensão dos potenciais responsáveis, na condição de indiretos, acarreta desestímulo à oferta de seguros ambientais a essas atividades, em virtude da insegurança e imprevisibilidade dos critérios que permitirão o acionamento dessas empresas por danos ocasionados por terceiros (CATALÁ, 1998). Por essa razão, uma definição criteriosa, constitucional e técnica é fundamental.

\subsection{Qual o grau de participação de um terceiro para sua responsabilização civil solidária em matéria ambiental? Critérios para responsabilidade do indireto}

Há que se destacar de plano o pressuposto de que, mesmo em uma matriz de responsabilidade objetiva, há a necessidade imprescindível de configuração e demonstração probatória do respectivo nexo causal entre conduta (ação ou omissão) e dano (FARBER; FREEMAN; CARLSON, 2014 e LEITE; AYALA, 2010). Se compararmos o sistema de responsabilidade civil subjetivo à matriz objetiva, constata-se haver um nítido deslocamento da ênfase da conduta (act-based), no caso da responsabilidade civil subjetiva, para o nível da atividade (effect activity-based), no caso da matriz objetiva (ABRAHAM, 2012). Nesse sentido, enquanto a primeira é mais centrada na prova da conduta subjetiva do autor do dano (em sua culpabilidade), a segunda será avaliada a partir dos deveres passíveis de serem impostos à uma atividade e que, descumpridos, colocam em risco terceiros e bens de interesse transindividual. Com a ocorrência dos danos (ou riscos intoleráveis), em uma matriz objetiva, há a submissão a um teste necessário no sentido de avaliar quem os ocasionou diretamente e quem tinha deveres de evitá-los (indireto). Por evidente, tais deveres estão atrelados ao conhecimento do risco, atribuição normativa de deveres de cuidado e condições materiais (competência e poder) para intervir e fiscalizar. A responsabilidade do indireto está ligada ao descumprimento desses deveres. Aqui, há a noção de deveres de segurança ou cuidado ambiental, sendo estes genericamente previstos no art. 225 da Constituição Federal e específico em diversas leis infraconstitucionais.

Portanto, deve ser esclarecido que a atividade causadora de um dano ambiental pode ter uma ou várias causas concorrentes. Esta seria a noção de poluidor direto previsto na legislação brasileira. Para fins didáticos, 
pode ser dito que os concausadores (aqueles que por ação ou omissão contribuíram diretamente para o dano) estão vinculados à reparação dos danos por uma causalidade física ou natural. A figura do indireto, contudo, tem sua responsabilização civil decorrente de um processo de atribuição normativa (causalidade normativa), oriunda necessariamente da violação de deveres ambientais. Em outras palavras, apesar de não ter sido a atividade degradadora imediata, haveria um dever deste em ter intervindo ou fiscalizado e que, deixando de fazê-lo, contribuiu determinantemente para a ocorrência do dano.

No caso dos atos comissivos, deve haver uma ação contributiva demonstrável (mesmo que por probabilidade) para a ocorrência do resultado lesivo. Os casos de omissão ensejam uma maior necessidade de critérios para a definição dos elementos violadores desses deveres de cuidado, para os quais atribui-se a responsabilidade do indireto. Não havendo a demonstração de omissão que viole deveres de cuidado ambiental, não há que se falar em responsabilidade do indireto. Nas tintas do Min. Teori Zavascki acerca de tais critérios, a solidariedade depende de um exame se essa “omissão foi ou não 'determinante' (vale dizer, causa suficiente ou concorrente) para a 'concretização ou o agravamento do dano"” (BRASIL, 2011).

Há pelo menos duas correntes que modulam diferentemente a responsabilidade civil do indireto em casos de danos ambientais. De um lado, a corrente mais afeta a uma maior amplitude e abrangência do sentido de poluidor indireto, havendo, para esta, a defesa da aplicação da responsabilidade objetiva, modulada pela teoria do risco integral, não apenas ao responsável direto, mas também ao indireto (BENJAMIN, 1998; STEIGLEDER, 2017). De outro, há entendimentos no sentido de que a responsabilidade civil do indireto deveria adotar um padrão inerente à teoria do risco criado (SAMPAIO, 2013; ZAPATER, 2013). Para a primeira corrente além de não se falar em excludentes de responsabilidade e não exigir a análise da ilicitude da atividade, a oneração probatória recai preponderantemente sobre o réu, no sentido de este ter de provar a ausência de nexo de causalidade ou da violação do dever de segurança. Herman Benjamin descreve o indireto, exemplificativamente, nos seguintes termos:

[...] o vocábulo [poluidor] é amplo e inclui aqueles que diretamente causam o dano ambiental (o fazendeiro, o industrial, o madeireiro, o minerador, o especulador), bem como os que indiretamente com ele contribuem, facilitando ou viabilizando a ocorrência do prejuízo (o banco, o órgão público licenciador, o engenheiro, o arquiteto, o incorporador, o corretor, o transportador...) (BENJAMIN, 1998, p. 37). 
Nesse sentido, vem sendo a aplicação da solidariedade em muitos casos em matéria ambiental submetidos ao STJ (BRASIL, 2003; 2005). Porém, chama-se a atenção para o fato de que, mesmo ante uma concepção ampla de poluidor indireto, deve haver a demonstração da causalidade (BRASIL, 2017b). Em outros casos, apesar de esta não ser expressa, a decisão parece não fazer grandes diferenciações acerca da responsabilidade do agente direto daquele denominado indireto (BRASIL, 2017a). Em defesa de uma interpretação maximalista da responsabilidade civil solidária, $\mathrm{o}$ STJ tem apresentado decisões que entendem não apenas pela solidariedade levar ao litisconsórcio facultativo (BRASIL, 2009a), como pela impossibilidade de denunciação à lide (BRASIL, 2009b). Síntese dessa perspectiva maximalista é dada pelo voto de lavra do Relator Min. Herman Benjamin ao afirmar que "[p]ara o fim de apuração do nexo de causalidade no dano urbanístico-ambiental e de eventual solidariedade passiva, equiparam-se quem faz, quem não faz quando deveria fazer, quem não se importa que façam, quem cala quando the cabe denunciar, quem financia para que façam e quem se beneficia quando outros fazem" (BRASIL, 2010). De outro lado, a aplicação da teoria do risco criado para a responsabilização do indireto repercute em analisar a possibilidade de excludentes de responsabilidade (força maior e caso fortuito). Ainda, em vez de o risco ser integralmente internalizado (como ocorre na teoria do risco integral), na teoria do risco criado dá azo à responsabilização apenas àquele risco capaz e apto a causar um dado dano.

Independentemente da teoria a ser adotada, parece-nos que a responsabilidade civil por danos ambientais exige, de um lado, a demonstração das concausas para a ocorrência do dano e, no caso do indireto, a demonstração de violação de um dever de cuidado ou de segurança. Tais deveres são legalmente impostos. A violação desses deveres tem relação direta com as atribuições (privadas) ou competências (públicas) das entidades envolvidas. Nesse sentido, essas atividades devem ter o conhecimento do risco que está envolvido e, além disso, terem a capacidade de intervir e fiscalizar. Deve, nesse sentido, ser demonstrado que o indireto não cumpriu com um dever normativo de cuidado, proteção e segurança ambiental. Em outras tintas, o concausador está necessariamente atrelado ao dano, enquanto o indireto o faz por omissão ou afronta a um dever normativo.

Nesse fio condutor, observa José Rubens Morato Leite que a exoneração da responsabilidade civil fundada na teoria do risco se dá quando o risco não foi criado, quando o dano não existiu ou quando o dano não guarda 
relação de causalidade com aquele que criou o risco (LEITE; AYALA, 2010). Do contrário, estar-se-ia diante de um inegável excesso de proteção, criando estímulos inadequados social, jurídica e economicamente. Pois, no caso de se responsabilizar quem não poderia "sequer ter colaborado para evitar o dano, é priorizada a reparação, sem que algum aspecto preventivo possa ser observado" (ZAPATER, 2013, p. 346).

Assim, estar-se-ia desestimulando o caráter preventivo e dissuasório, segundo Zapater (2017), desarticulando o caráter e potencial da responsabilidade civil como elemento jurídico indutor de comportamentos de gestão de risco. Portanto, o agente direto, assim como o concausador (ação ou omissão), respondem solidariamente pelos danos ambientais decorrentes de suas condutas que, ativa ou omissivamente, geraram os riscos que, num segundo momento, redundaram em dano. Já o responsável indireto (Administração Pública, instituição financiadora, parceiro ou colaborador econômico, entre outros) pode ser responsabilizado quando demonstrado que este detinha conhecimento da situação de risco de terceiros e, detendo condições para intervir, não agiu para sua contenção, omitindo-se no dever de cuidado ou segurança ambiental, que lhe era exigível (BRASIL, 2009c).

De outro lado, deve-se atentar para a questão temporal na relação de causa e consequência. Nesse sentido, a falha no dever de fiscalizar do indireto (público ou privado), por exemplo, deve ser anterior ao dano e não posterior a ele (FARIAS; BIM, 2017). Uma exceção a essa regra lógica geral se dá no sentido da obrigação denominada propter rem. Essas obrigações acompanham o bem imóvel, decorrendo deste, mesmo que as atividades degradadoras tenham sido praticadas por terceiros anteriormente à aquisição da propriedade ou da posse pelo indireto. No entanto, deve-se atentar para o fato de essa previsão encontrar assento legal para os casos específicos de proteção florestal (art. $2^{\circ}, \S 2^{\circ}$, da Lei n. 12.651/12). Trata-se, portanto, de previsão específica e excepcional, de atribuição de responsabilidade sem a necessidade de demonstração de contribuição ou dever de cuidado (conhecimento do risco e aptidão para evitar o dano).

\section{CONSIDERAÇÕES FINAIS}

Apesar de um consenso doutrinário e jurisprudencial acerca da aplicação do instituto da solidariedade à reparabilidade de danos ambientais, a matéria acerca dos limites dessa aplicação é bastante tormentosa. Após um primeiro momento de consolidação bastante ampla da solidariedade e 
da imputação civil ao indireto, ainda é pertinente uma reflexão crítica dos critérios para sua imposição. Nesse sentido, de amadurecimento temporal do instituto da solidariedade, que o presente artigo pretende lançar luzes.

Primeiro, cumpre descrever a distinção clássica entre o sistema de responsabilidade compartilhada e o da solidária. Esses sistemas consistem nos padrões internacionalmente aplicáveis a casos de danos ambientais causados por uma pluralidade de agentes. Com critérios diferentes, estes lançam o ônus da prova e da remediação das áreas órfãs sobre diferentes atores. A compartilhada privilegia uma maior atenção às responsabilidades e participação de cada uma das partes que tenham causado um potencial dano. De outro lado, esta atribui às partes afetadas o ônus da prova acerca da demonstração da participação de cada um dos agentes (em parcelas determinadas) e seus percentuais. Ainda, em um modelo puro, em não havendo tal prova, as áreas ficarão "órfãs", onerando preponderantemente o proprietário ou o responsável pela remediação. Já a solidariedade, ao contrário, onera preponderantemente aqueles acusados de participarem de uma degradação ambiental, lhes cabendo a prova negativa de participação no dano. Caso não cumpram com esse encargo probatório, poderão ser responsabilizados pelo todo, o que abrange as áreas "órfãs". A solidariedade, no entanto, se aplicada com demasiada amplitude, acarreta um risco moral de desestimular comportamentos preventivos e de gestão de riscos, diante da expectativa de que uma vasta cadeia estará obrigada a recuperar o dano caso ele ocorra. Por vezes, as atividades alheias à produção de risco são afetadas pela solidariedade em nosso sistema, levanto a um efeito colateral de insegurança jurídica e enfraquecimento da função dissuasória da responsabilidade civil. Apesar de haver uma nítida escolha pelo sistema da solidariedade em nosso Direito, isso não afasta a previsão, em alguns casos normativa, de responsabilidade compartilhada, como é o caso emblemático da Lei de Política Nacional de Resíduos Sólidos.

Após abordar a solidariedade em sua matriz geral, houve a necessidade de enfrentar o tema das nuances da aplicação desse instituto à matéria e aos casos ambientais. É neste momento que o presente texto demonstra a importância de uma delimitação conceitual e estrutural do instituto da solidariedade. Uma análise sofisticada do instituto tem a função de permitir delinear as fronteiras da solidariedade, demonstrando os casos em que esta, excepcionalmente, não é aplicada. Entre os casos, trazidos no presente artigo, capazes de excluir a incidência da solidariedade, tem-se eventos (i) de dano ambiental divisível ou fragmentável, assim como aqueles submetidos 
normativamente ao regime da responsabilidade compartilhada; (ii) em que o cumprimento das obrigações de recuperação de dano depende necessariamente de atividades ou patrimônio de terceiros; e (iii) de contribuições insignificantes.

Finalmente, aborda-se o poluidor indireto, como figura jurídica que pode vir a ser responsabilizado pelo dano ambiental causado diretamente por outras atividades. Trata-se de casos, por exemplo, de responsabilidade civil do Estado por omissão, de instituições financeiras pelo financiamento de atividades lesivas, de clientes de central de resíduos que vem encerrar irregularmente suas operações, de compradores de produtos que gerem ao longo do transporte algum dano, de desconsideração da personalidade jurídica.

A análise detalhada sobre tais definições demonstra que os responsáveis diretos são aqueles que contribuem, em suas causas e concausas, para um dano ambiental, no exercício de suas atividades e omissões imediatamente identificáveis causalmente. De outro lado, o indireto, consiste em atores que, apesar de não terem participação direta na atividade causadora do dano ambiental, acabam contribuindo pela violação de algum dever normativo de segurança ambiental, e que possa lhe ser atribuído (causalidade normativa). A busca pela delimitação conceitual do poluidor indireto é capaz de, após uma análise crítica, revelar os critérios jurídicos para a delimitação do âmbito de aplicação da imputação civil deste. Assim, pode ser sintetizado que o poluidor direto consiste naquelas atividades que, ao produzirem situações de risco, contribuem diretamente para o dano ambiental, por ação ou omissão. O poluidor indireto, por seu turno, é passível de responsabilização quando, apesar de não produzir diretamente os riscos envolvidos, viola um dever normativo de segurança e cuidado ambiental. Essa violação aos deveres de segurança ambiental decorre do conhecimento dos riscos por este, de sua capacidade e competência para evitá-los e, finalmente, da configuração de uma omissão em intervir e fiscalizar.

\section{REFERÊNCIAS}

ABRAHAM, K. S. The forms and functions of Tort Law. 4. ed. New York: Fundation Press, 2012.

ANTUNES, P. B. O conceito de poluidor indireto e a distribuição de combustíveis. Revista SJRJ, Rio de Janeiro, v. 21, n. 40, p. 229-244, ago. 2014. 
ANTUNES, P. B. Direito Ambiental. 18. ed. São Paulo: Atlas, 2016.

BENJAMIN, A. H. Responsabilidade civil pelo dano ambiental. Revista de Direito Ambiental, São Paulo, n. 9, p. 5-52, 1998.

BERGKAMP, Lucas. Liability and Environment. The Hague: Kluwer Law International, 2001.

BRASIL. Superior Tribunal de Justiça (1. Turma). Agravo Regimental no Recurso Especial n. 1.001.780/PR. Relator: Ministro Teori Albino Zavascki. Brasília, DF, 27 de setembro de 2011. DJe 04 dez. 2011.

BRASIL. Lei n. 12.651, de 25 de maio de 2012. Dispõe sobre a proteção da vegetação nativa; altera as Leis nos 6.938, de 31 de agosto de 1981, 9.393, de 19 de dezembro de 1996, e 11.428, de 22 de dezembro de 2006; revoga as Leis nos 4.771, de 15 de setembro de 1965, e 7.754, de 14 de abril de 1989, e a Medida Provisória n. 2.166-67, de 24 de agosto de 2001; e dá outras providências. Brasília, DF: Presidência da República, 2012. Disponível em: http://www.planalto.gov.br/ccivil_03/_ato2011-2014/2012/lei/ 112651.htm. Acesso em: 24 out. 2020.

BRASIL. Superior Tribunal de Justiça (2. Turma). Recurso Especial n. 843.978/SP. Relator: Ministro Herman Benjamin. Brasília, DF, 21 de setembro de 2010. DJe 09 mar. 2013.

BRASIL. Superior Tribunal de Justiça (1. Turma). Recurso Especial n. 1.383.707/SC. Relator: Ministro Sérgio Kukina. Brasília, DF, 08 de abril de 2014. DJe 05 jun. 2014.

BRASIL. Lei n. 13.105, de 16 de março de 2015. Código de Processo Civil. Brasília, DF: Presidência da República, 2015. Disponível em: http:// www.planalto.gov.br/ccivil_03/_ato2015-2018/2015/lei/113105.htm. Acesso em: 24 out. 2020.

BRASIL. Superior Tribunal de Justiça (2. Turma). Agravo Regimental no Recurso Especial n. 839.492/SP. Relator: Ministro Herman Benjamin. Brasília, DF, 15 de dezembro de 2016. DJe 06 mar. 2017a.

BRASIL. Superior Tribunal de Justiça (2. Turma). Agravo Regimental no Recurso Especial n. 277.167/MG. Relator: Ministro Og Fernandes. Brasília, DF, 14 de março de 2017. DJe 20 mar. 2017b.

BRASIL. Superior Tribunal de Justiça (2. Turma). Recurso Especial n. 1.602.106/PR. Relator: Ministro Ricardo Villas Bôas Cueva. Brasília, DF, 25 de outubro de 2017. DJe 22 nov $2017 \mathrm{c}$. 
CARVALHO, D. W. Solidariedade ambiental e a figura jurídica do poluidor indireto. In: CARVALHO, D. W. Gestão jurídica ambiental. São Paulo: Revista dos Tribunais, 2017. p. 353-412.

CASTRO, C. R.; REZENDE, E. N. Uma análise crítica sobre a responsabilidade civil por dano ambiental nos Estados Unidos da América. Revista do Curso de Mestrado em Direito - RVMD, Brasília, DF, v. 9, n. 2, p. 1-20, jul./dez. 2015.

CATALÁ, L. G. Responsabilidad por daños al medio ambiente. Pamplona: Arazandi, 1998.

CAVALIERI FILHO, S. Programa de responsabilidade civil. 10. ed. São Paulo: Atlas, 2012.

COE - COUNCIL OF EUROPE. Convention on Civil Liability for Damage Resulting from Activities Dangerous to the Environment. Lugano, 21 jun. 1993. Disponível em: https://rm.coe.int/CoERMPublicCommonSearchServices/DisplayDCTMContent?documentId=090000168007c079. Acesso em: 15 out. 2020.

COELHO, F. U. Curso de Direito Civil. São Paulo: Saraiva, 2012.

CRUZ, B. M. Responsabilidade civil pelo dano ecológico: alguns problemas. Revista de Direito Ambiental, São Paulo, ano 2, n. 5, p. 5-52, jan./ mar. 1997.

DANTAS, M. B. Atualidades sobre a ação civil pública ambiental. In: MILARÉ, É. (Coord.) A ação civil pública após 25 anos. São Paulo: Revista dos Tribunais, 2010. p. 573-589.

FARBER, D.; FREEMAN, J.; CARLSON, A. Cases and materials on Environmental Law. 9. ed. St. Paul: West, 2014.

FARBER, D. A.; FINDLEY, R. W. Environmental law in a nutshell. 8. ed. St. Paul: West, 2010.

FARIAS, C. C.; ROSENVALD, N. Curso de Direito Civil: obrigações. 6. ed. v. 2. Salvador: Juspodivm, 2012.

FARIAS, T.; BIM, E. F. O poluidor indireto e a responsabilidade civil ambiental por dano precedente. Veredas do Direito, Belo Horizonte, v. 14, n. 28, p. 127-146, jan./abr. 2017.

FAURE, M. Environmental liability. In: FAURE, M. Tort Law and economics. Cheltenham: Edward Elgar, 2009. p. 247-286. 
FREITAS, G. P.; CARDOSO, S. A. Os responsáveis pela degradação ambiental são coobrigados solidários, formando-se, em regra, nas ações civis públicas ou coletivas, litisconsórcio facultativo. In: PADILHA, N. S. (Coord.). Teses jurídicas dos tribunais superiores: Direito Ambiental. v. I. São Paulo: Revista dos Tribunais, 2017. p. 171-183.

GOMES, O. Obrigações. 11. ed. Rio de Janeiro: Forense, 1996.

GONZÁLEZ, A. R. El daño ecológico puro: la responsabilidad civil por el deterioro del medio ambiente. Girona: Universitat de Girona, 2005.

GREENBERG, J. M. Superfund and tort common law: why courts should adopt contemporary analytical framework for divisibility of harm. Minnesota Law Review, Minneapolis, v. 103, n. 2, p. 999-1039, dez. 2018.

LEITE, J. R. M.; AYALA, P. A. Dano ambiental: do individual ao coletivo extrapatrimonial. Teoria e prática. 3. ed. São Paulo: Revista dos Tribunais, 2010.

LEMOS, P. F. I. Resíduos sólidos e responsabilidade civil pós-consumo. 3 . ed. São Paulo: Revista dos Tribunais, 2014.

LUCARELLI, F. D. Responsabilidade civil por dano ecológico. Revista dos Tribunais, São Paulo, ano 83, v. 700, p. 7-26, fev. 1994.

MACHADO, P. A. L. Direito Ambiental brasileiro. 26. ed. São Paulo: Malheiros, 2018.

MADDEN, M. S. Joint and several liability and environmental harm in the 1990's. Fordham Environmental Law Review, New York, v. 9, n. 3, p. 483-494, 2017.

MARTIN, G. La responsabilité civile pour les dommages à l'environnement et la Convention de Lugano. Revue Juridique de l'Environmement, Strasbourg, n. 2-3, p. 121-136, 1994.

MILARÉ, É. Direito do Ambiente. 10. ed. São Paulo: Revista dos Tribunais, 2015.

MOREIRA, D. A. Responsabilidade ambiental pós-consumo: prevenção e reparação de danos à luz do princípio do poluidor-pagador. São Paulo: Letras Jurídicas, 2015.

NERY JUNIOR, N.; ANDRADE NERY, R. M. Código de processo civil comentado e legislação extravagante. 14. ed. São Paulo: Revista dos Tribunais, 2014. 
OLIVEIRA, A. P. Causalidade e imputação na responsabilidade civil ambiental. Coimbra: Almedina, 2007.

PERALES, C. M. La responsabilidad civil por daños al medio ambiente. Madrid: Civitas, 1993.

SAMPAIO, R. Responsabilidade civil ambiental das instituições financeiras. Rio de Janeiro: Campus Jurídico, 2013.

SILVA, J. A. Direito Ambiental Constitucional. São Paulo: Malheiros, 1994.

STEIGLEDER, A. M. Responsabilidade Civil Ambiental: as dimensões do dano ambiental no direito brasileiro. 3. ed. Porto Alegre: Livraria do Advogado, 2017.

UNITED STATES. Supreme Court of the United States. United States v. Monsanto Co., 858 F.2d 160 (4th. Circ. 1988) e United States v. ChemDyne Corp., 572 F. Supp. 802 (S.D. Ohio).

UNITED STATES. Supreme Court of the United States. Pinal Creek Group v. Newmont Mining Corp., 118 F. 3d 1298 (9th Cir. 1997).

ZAPATER, T. C. Áreas contaminadas e reparação integral - diferença entre obrigação propter rem e a responsabilidade civil por dano ambiental. In: MILARÉ, É. (Coord.). Revista do Advogado: Direito Ambiental. São Paulo: AASP, 2017. p. 218-228.

ZAPATER, T. C. Responsabilidade civil do poluidor indireto e do cocausador do dano ambiental. In: ROSSI, F. F. et al. (Coords.). Aspectos controvertidos do Direito Ambiental: tutela material e tutela processual. Belo Horizonte: Fórum, 2013. p. 339-377.

Artigo recebido em: 19/02/2020.

Artigo aceito em: 28/10/2020.

\section{Como citar este artigo (ABNT):}

CARVALHO, D. W. Limites à responsabilidade solidária ambiental e à caracterização do poluidor indireto. Veredas do Direito, Belo Horizonte, v. 17, n. 39, p. 63-97, set/dez. 2020. Disponível em: http://www.domhelder. edu.br/revista/index.php/veredas/article/view/1774. Acesso em: dia mês. ano. 